\title{
Fatal Disseminated Strongyloidiasis in an Immunocompromised Former War Prisoner of the Japanese
}

Col (Retd) J B Stewart, MB, ChB, FRCPath, DTM\&H, L/RAMC

Professor of Pathology, Royal Army Medical College, Millbank

Maj B J Heap, $M A, M B, M R C P, R A M C$

Senior Specialist in Medicine, Queen Elizabeth Military Hospital, Woolwich

ABSTRACT: An ex-Far East prisoner of war (FEPOW) treated with corticosteroids for severe polymyositis died frommultisystem strongyloidiasis and pyogenic meningitis. At necropsy larvae were widely disseminated in the lungs, liver, $\rightarrow$ heart and brain.

\section{Introduction}

Strongyloides stercoralis is a long living intestinal nematode which infects a large portion of the world's population. It is particularly prevalent among former Far East prisoners of war (FEPOWs) especially those who survived the notorious Japanese Thai-Burma (Siam) railway camps ${ }^{1-3}$. Forty-eight years have passed since these men returned home from the prison camps in South East Asia but many of them remain infected with this persistent worm and are at serious risk of developing disseminated strongyloidiasis if their immune systems are compromised ${ }^{4,5}$. We report such a case of an exFEPOW who died with disseminated Strongyloides stercoralis following corticosteroid treatment of polymyositis.

\section{Case Report}

A 73 year old former Far East prisoner of war was admitted to Queen Elizabeth Military Hospital (QEMH), Woolwich on 16 February 1981 for tropical disease screening and investigation of severe breathlessness on moderate exertion. He had no fever, sweats, weight loss, anorexia, rashes or gastro-intestinal symptoms. While in Japanese prison camps he had worked on the notorious Burma Railway and had suffered cerebral malaria, beri-beri, malnutrition, amoebic dysentery and transient visual upset. He complained of "asthma" for 9-10 years before admission. Investigations revealed chronic obstructive airways disorder with bronchospasm and dyspnoea of effort. Loss of vibration sense at both ankles was noted.

There was cervical spondylosis. Slight blood eosinophilia $\left(0.8 \times 10^{9} / \mathrm{L}\right)$ was noted on routine diagnostic work-up but as there was no skin rash and three stool specimens were reported negative for parasites, specific treatment for strongyloidiasis was withheld. For five years prior to this first admission he had been taking 5 $\mathrm{mg}$ Prednisolone twice daily and he was discharged to continue this treatment.
Almost exactly one year later on 20 February 1982 heo was readmitted to QEMH with an acute exacerbation of $\vec{\omega}$ his respiratory symptoms. On examination there were signs of chronic obstructive airways disease and right오 basal pneumonitis. He was pyrexial $\left(38^{\circ} \mathrm{C}\right)$, breathless at rest, dehydrated and centrally cyanosed with cosello peripheries. His breathlessness involved markedt? increased accessory respiratory muscle action. The pule $\vec{C}$ rate was 120/minute and regular. BP was 110/雨) millimetres of mercury.

Chest X-ray revealed a rounded lesion at the righ apex and ill-defined left basal pneumonic change. ECG $\overrightarrow{0}$ indicated infero-lateral ischaemic changes. \&nco admission $\mathrm{Hb}$ was $14.8 \mathrm{grams} / \mathrm{dl}$, WBC $9.8 \times 10^{9} / \mathrm{L}$ withat normal differential and no eosinophilia.

He was treated initially with Ampicillin $500 \mathrm{mg}$ IV sT hourly and Hydro-cortisone $500 \mathrm{mg}$ IV stat. Over the course of the next three days the white blood count rose $\frac{\mathrm{O}}{\mathrm{O}}$ to $21.4 \times 10^{9} / \mathrm{L}$ with neutrophilia. ESR increased from $20 \cong$ to $49 \mathrm{~mm}$ in the hour (Westergren). Marked generalised $\overrightarrow{\overrightarrow{0}}$ muscle tenderness with weakness was noted. A cardiac 3 enzyme profile showed a CPK rise from an initial high value of $1558 \mathrm{IU}$ to $4,082 \mathrm{IU}$ on day three. In view of this? CPK elevation and the marked muscle tenderness, a diagnosis of polymyositis was made. Erythromycin and Trimethoprim were substituted for Ampicillin and Prednisolone was increased to $10 \mathrm{mg}$ four times daily. $\mathrm{A}_{\overline{\mathrm{D}}}^{\vec{े}}$ transient non-specific widespread macular rash on the $\frac{\mathcal{O}}{F}$ trunk was attributed to Trimethoprim.

Some slight improvement occurred and he appeared brighter but weakness and muscle wasting persisted. On the night of 27 March 1982 he deteriorated dramatically and lapsed into coma, dying the following day.

\section{Necropsy Findings}

A post-mortem was performed 48 hours after death. $\widetilde{\sigma}$ There was severe generalised muscle wasting and 0 microscopical examination of skeletal muscle groups స్ట 
disclosed evidence of severe muscular atrophy with widespread fibre degeneration, inflammatory reaction (mainly histiocytic) and fibrous replacement without fat or signs of muscle regeneration - the overall picture being consistent with advanced late stage polymyositis. There was diffuse purulent leptomeningitis from which Escherichia coli was isolated in pure culture. Both lungs had the honeycombed appearace of chronic interstitial fibrous lung disease with apical emphysematous bullae. There was also patchy bronchopneumonic consolidation, haemorrhage and congestion. A small nonspecific abscess was found in the right lower posterior lobe; there were scattered pulmonary emboli in the periphery of both lungs. Microscopical examination revealed a complex picture of diffuse chronic interstitial lung fibrosis, focal septic infarcts, bronchopneumonia, diffuse alveolar haemorrhage with scattered microgranulomas and microabscesses. The arresting finding was the presence of widespread Strongyloides larvae. Adult Strongyloides and larvae were conspicuous in the duodenal mucosa (Fig 1) with a moderate inflammatory reaction to their presence in the lamina priopria and muscularis where an occasional microgranuloma was noted. Larvae were most numerous in the lungs where they were present both in microgramulomas and microabscesses as well as lying free in the adventitia around blood vessels without any surrounding inflammatory reaction (Fig 2). Larvae were also readily demonstrated in the liver both in microgranulomas and lying free. Free lying larvae were also found in the heart muscle. An isolated larva was found in the cerebral white matter but with a prolonged search failed to reveal any others in the brain or in the leptomeninges. The prostate contained a small latent adenocarcinoma. A Meckel's diverticulum and sigmoid diverticulosis were present.

The colon was otherwise unremarkable and showed no mucosal ulceration. The kidneys showed only nonspecific changes and larvae were not found. Scattered microthrombi associated with cutaneous and visceral petechiae suggested septicaemia and DIC as the terminal event complicating disseminated strongyloidiasis and coliform meningitis in corticosteroid-treated polymyositis.

\section{Discussion}

In addition to the well known risks of bacterial, viral, fungal and protozoal infections severe, sometimes fatal, disseminated Strongyloides infection occurs in immunosuppressed patients with a variety of underlying conditions including malignancy, nephrotic syndrome, corticosteroid therapy, malnutrition, hypogammaglobulinaemia, tuberculosis and chronic renal failure ${ }^{6}$. Such an hyperinfection syndrome was discovered in our patient at post-mortem. As in our case bacterial sepsis often contributes to a fatal outcome and associated

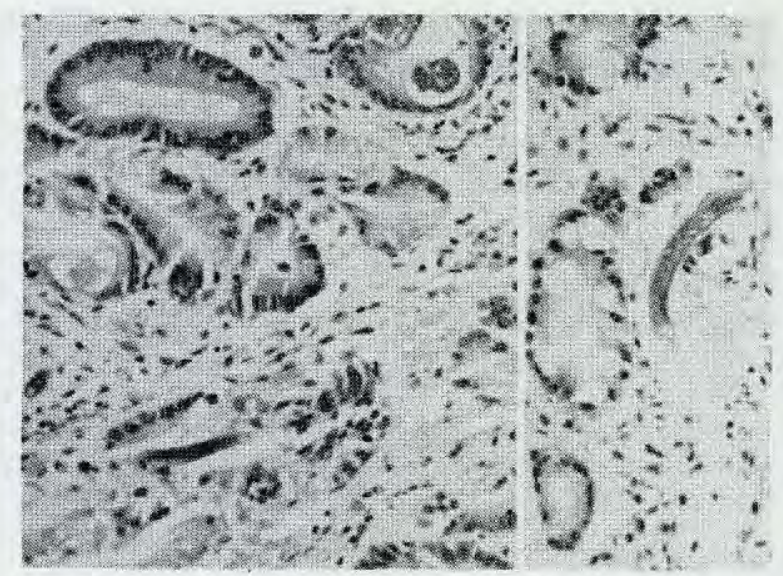

Fig 1. Strongyloides larvae in duodenal mucosa.

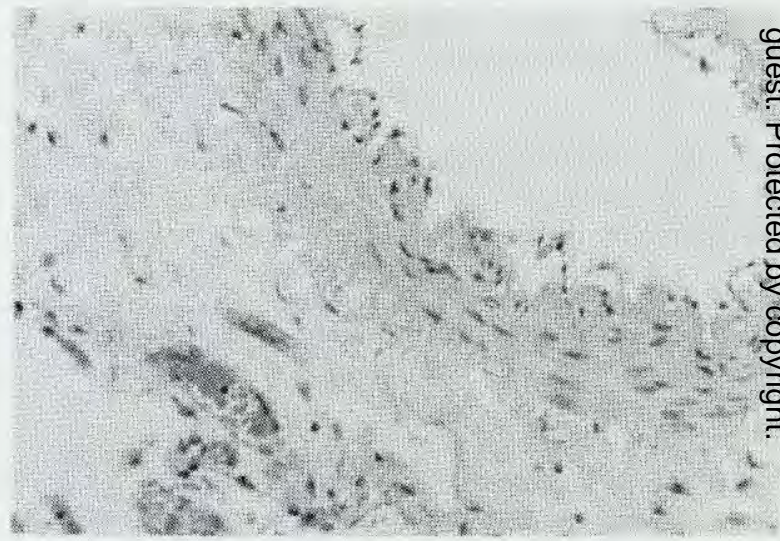

Fig. 2. Adult Strongyloides and larvae in walls of pulmonary arterioles.

pyogenic meningitis also is well documented ${ }^{8}$. Central nervous system involvement with Strongyloides Stercoralis has previously been recognised in only a few cases at post-mortem examination ${ }^{9.10}$ and in two cases ante mortem ${ }^{11}$. Massive systemic Strongyloides invasion has also been previously documented in a corticosteroidtreated patient with severe polymyositis ${ }^{12}$.

Our patient had been a prisoner of war in the Far East and had suffered a number of other tropical diseases during captivity when he most probably acquired his Strongyloides infection. Of interest is the fact that he never had symptoms and his strongyloidiasis remained undiagnosed despite hospital tropical disease screening in 1980. Many undiagnosed cases of strongyloidiasis must still exist among these former FEPOWs living mostly in Britain, Australia and North America; they are now in that age group some 40 years later when the 
increased risk of certain conditions predisposing to immune dysfunction should be anticipated. Stool examination for Strongyloides, even in skilled hands, is unreliable. The Enterotest duodenal capsule (string test) has been reported to give greater reliability than examination of stool specimens ${ }^{15,14}$. Preliminary results at Queen Elizabeth Military Hospital attest to the higher yield of parasites using the simple string test.

The patient we report had polymyositis, an inflammatory myopathy of unknown cause. There is no evidence to link this condition with chronic worm infestation. An incidental (latent) prostatic carcinoma was found post mortem. Fewer than $10 \%$ of patients with adult onset polymyositis have a possible associated malignant condition and the inter-relationship with muscle involvement is unclear. The final immunological status of our patient was certainly complex. In addition to chronic strongyloidiasis, severe polymyositis and latent malignancy, he also had idiopathic chronic interstitial lung fibrosis, another condition which may be immune-mediated. The final insult to his immune system came from high doses of corticosteroids mandated by life-threatening polymyositis. Our patient did not receive any anti-helminthic treatment. Thiabendazole is an effective drug in strongyloidiasis and there is a case for prophylactic use of this drug in all FEPOWs and others who have lived or live in endemic areas $^{7}$. Conventional three day courses of treatment for infection are however inadequate in immunosuppressed patients who require longer and repeated treatment with Thiabendazole plus stool and duodenal aspiration to ensure eradication ${ }^{4}$.

The diagnosis of strongyloidiasis is made only if someone thinks of it. Delay may prove catastrophic. A high index of suspicion is needed, particularly in patients prior to initiating chemotherapy or before giving immune suppressive medications or corticosteroids to patients with non-neoplastic conditions such as renal allografts, nephrotic syndrome or connective tissue diseases.

\section{Acknowledgements}

We thank Lt Col G O Cowan MB, FRCP for allowing us to report his patient and for reading the manuscript. $\stackrel{\mathbb{D}}{\mathcal{Q}}$ We are grateful to Miss J G Pearce, Assistant Librarian 8 RAM College for the literature search. S/SGT Sharp, 음 FIMLS, RAMC and S/Sgt Ferguson, RAMC gave ?. technical assistance. The Department of Photography, $\overrightarrow{\vec{F}}$ RAM College kindly prepared the photographs. We are indebted to Mrs C M Stewart, Miss P A Jones and Miss F So for typing the manuscript.

\section{REFERENCES}

1. GILL, G V, BELL, D R. Strongyloides stercoralis infection in former Far East prisoners of war. BR Med J 1979, ii: $\overrightarrow{0}$ 572-74.

2. GROVE, D I. Strongyloidiasis in allied ex-prisoners of war in South-east Asia. BR Med J 1980; 280: 598-601.

3. GILL, G V, BELL, D R. Strongyloidiasis in ex-prisoners of war in South east Asia. BR Med J 1980; 280: 1319.

4. Scowden, E B, Schaffner, W, Stone, W J. Overwhelming strongyloidiasis: an unappreciated opportunistic infection. Medicine (Baltimore) 1978; 57: 527-44. $\omega$

5. Bradley, S L, Dines, D E, BREwer N S. Disseminated Strongyloides stercoralis in an immunosuppressed host Mayo Clin Proc 1978, 53: 332-35.

6. Shelhamer, J H, Neva, F A, FinN, D R. Persiste strongyloidiasis in an immunodeficient patient. Am J Trop 응 Med Hyg 1982; 31: 746-51.

7. Weller, I V D, Copland, P, Gabriel, R. Strongyloides stercoralis infection in renal transplant recipients. $\mathrm{Br} M$ लब $J$ 1981; 282: 524 .

8. Vishwanath, S, Baker, R A, Mansheim, B J. Strong loides infection and meningitis in an immunocompromised host. Am J Trop Med Hyg 1982; 31: 857-8.

9. OWOR, R, WAMUKOTA, W M. A case of fatal strong 8 loidiasis with Strongyloides larvae in the meninges Trans R Soc Trop Med Hyg 1977; 70: 497-9.

10. Neefe, L I, Pinilla, O, Garagusi, V F, Bauer, if Disseminated strongyloidiasis with cerebral involvement. A complication of corticosteroid therapy. AM J Med 1973 55: $832-8$.

11. Meltzer, R S, Singer, C, Armstrong, D, Mayer, M, KNAPPER, W H. Antemortem diagnosis of central nervous system strongyloidiasis. AM J Med Sci 1979; 277: 91-8.

12. MCNeEly, D J, InOUYe, TAM, P Y, Ripley, S D. Acute respiratory failure due to strongyloidiasis in polymyositis. J Rheumatol 1980; 7: 745-50.

13. GILl, G V, BeLl, D R. Longstanding tropical infections amongst former war prisoners of the Japanese. Lancet 1982; 1: 958-9.

14. Goldsmid, J M, Davies, N. Diagnosis of parasitic infections of the small intestine by the Enterotest duodenal capsule. Med J Aust 1978; 1(9): 519-20. 